\title{
Erratum
}

\section{The human locus coeruleus complex: an immunohistochemical and three dimensional reconstruction study}

\section{K.G. Baker, I. Törk, J.-P. Hornung, and P. Halasz}

Exp Brain Res (1989) 77:257-270

Due to an error of the printer, Figure 2 on page 260 of the above article has been printed upside down and without the scalebar. This missing scalebar together with Figure 2 in its correct upright position will be found below.

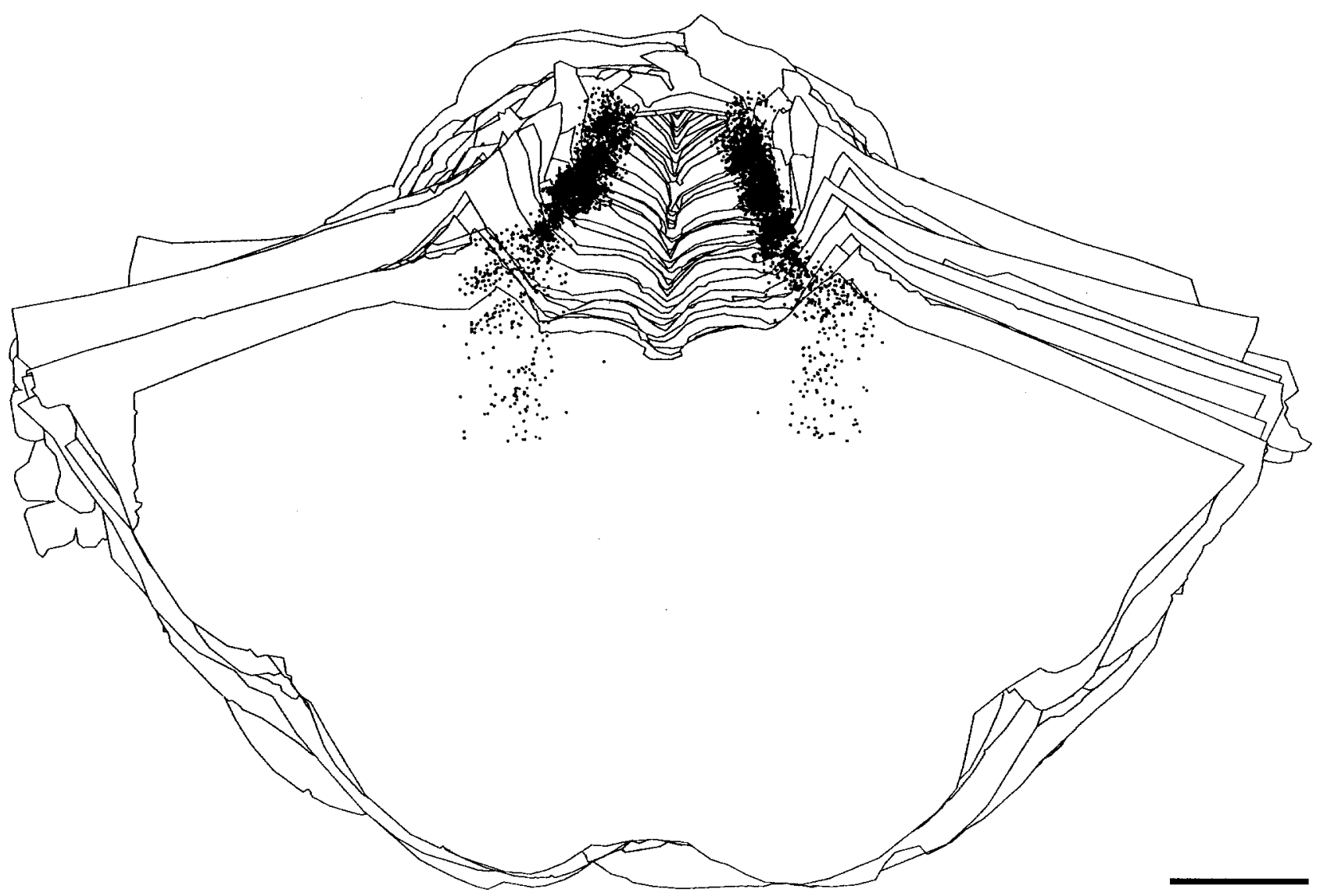

Fig. 2. Three dimensional computer reconstruction of a series of spaced sections from the human LC and SubC seen in a caudorostral direction. Each dot represents one cell. As only every eighth section was used, the displayed dots represent only one eighth of the TH-IR population of the LC. The total length of the LC was calculated to be $12 \mathrm{~mm}$. The scattered dots in the foreground (caudal pons) represent cells of the SubC in the ponetine tegmentum, whereas the dense accumulation of cells in the pons and isthmus belongs to the $\mathrm{LC}$ proper $\mathrm{Bar}=5 \mathrm{~mm}$ 